\title{
DSP-Based Speed Adaptive Flux Observer of Induction Motor
}

Hisao Kubota, Member, IEEE, Kouki Matsuse, Senior Member, IEEE, and Takayoshi Nakano

\begin{abstract}
This paper presents a new method of estimating the speed of an induction motor. This method is based on adaptive control theory: Experimental results of a direct field-oriented induction motor control without speed sensors are presented.
\end{abstract}

\section{INTRODUCTION}

$\mathbf{T}$ THE INDIRECT field-oriented control method is widely used for induction motor drives. This method needs a speed sensor such as a shaft encoder not only for speed control but also for torque control. Although the direct fieldoriented control method with a flux estimator, which uses a pure integrator, does not need the speed sensor for torque control, this method is not practical. This is because the flux estimator does not work well in a low speed region. The pole of the flux estimator is on the origin of the $s$ plane, and it is very sensitive to the offset of the voltage sensor and the stator resistance variation.

However, a speed sensor cannot be mounted in some cases, such as motor drives in a hostile environment or high speed motor drives. Several field-oriented control methods without speed sensors have been proposed [1]-[5]. Some of them can be applied only to the indirect field-oriented control and some to the direct field-oriented control, and stability has not been explained clearly. In addition, some methods are unstable in a low speed region, because pure integration is used for the flux calculation as mentioned above.

Therefore, we have proposed a new method of estimating induction motor speed, a speed adaptive flux observer, based on adaptive control theory [6]. The proposed scheme uses the state observer which can allocate poles arbitrarily. Therefore, it can be applied to the direct field-oriented control, even in a low speed region. The validity of the proposed method is verified using experimentation. The speed adaptive flux observer is implemented on a digital signal processor (DSP: NEC $\mu$ PD77230).

\section{SPEED ADAPTIVE FLuX OBSERVER}

\section{A. Flux Observer of Induction Motor}

An induction motor can be described by following state

Paper IPCSD 92-34, approved by the Industrial Drives Committee of the IEEE Industry Applications Society for presentation at the 1991 IAS Annual Meeting, Dearborn, MI, September 28-October 4. Manuscript released for publication August 17, 1992.

H. Kubota and K. Matsuse are with the Department of Electrical Engineering, Meiji University, Kawasaki, Japan.

T. Nakano is with Fuji Electric Company, Tokyo, Japan. IEEE Log Number 9207102. equations in the stationary reference frame.

$$
\begin{aligned}
\frac{d}{d t}\left[\begin{array}{c}
i_{s} \\
\phi_{r}
\end{array}\right] & =\left[\begin{array}{ll}
A_{11} & A_{12} \\
A_{21} & A_{22}
\end{array}\right]\left[\begin{array}{c}
i_{s} \\
\phi_{r}
\end{array}\right]+\left[\begin{array}{c}
\boldsymbol{B}_{1} \\
0
\end{array}\right] v_{s} \\
& =\boldsymbol{A} x+\boldsymbol{B} v_{s} \\
i_{s} & =\boldsymbol{C} x
\end{aligned}
$$

where

$$
\begin{aligned}
i_{s} & =\left[i_{d s} i_{q s}\right]^{T} \quad \text { stator current } \\
\phi_{r} & =\left[\phi_{d r} \phi_{q r}\right]^{T} \quad \text { rotor flux } \\
v_{s} & =\left[v_{d s} v_{q s}\right]^{T} \quad \text { stator voltage } \\
A_{11} & =-\left\{R_{s} /\left(\sigma L_{s}\right)+(1-\sigma) /\left(\sigma \tau_{r}\right)\right\} \boldsymbol{I}=a_{r 11} \boldsymbol{I} \\
A_{12} & =M /\left(\sigma L_{s} L_{r}\right)\left\{\left(1 / \tau_{r}\right) \boldsymbol{I}-\omega_{r} \boldsymbol{J}\right\}=a_{r 12} \boldsymbol{I}+a_{i 12} \boldsymbol{J} \\
A_{21} & =\left(M / \tau_{r}\right) \boldsymbol{I}=a_{r 21} \boldsymbol{I} \\
A_{22} & =-\left(1 / \tau_{r}\right) \boldsymbol{I}+\omega_{r} \boldsymbol{J}=a_{r 22} \boldsymbol{I}+a_{i 22} \boldsymbol{J} \\
B_{1} & =1 /\left(\sigma L_{s}\right) \boldsymbol{I}=b_{1} \boldsymbol{I} \\
\boldsymbol{C} & =\left[\begin{array}{ll}
\boldsymbol{I} & 0
\end{array}\right] \\
\boldsymbol{I} & =\left[\begin{array}{ll}
1 & 0 \\
0 & 1
\end{array}\right] \quad \boldsymbol{J}=\left[\begin{array}{rr}
0 & -1 \\
1 & 0
\end{array}\right]
\end{aligned}
$$

$R_{s}, R_{r} \quad$ stator and rotor resistance

$L_{s}, L_{r} \quad$ stator and rotor self inductance

$M \quad$ mutual inductance

$\sigma \quad$ leakage coefficient, $\sigma=1-M^{2} /\left(L_{s} L_{r}\right)$

$\tau_{r} \quad$ rotor time constant, $\tau_{r}=L_{r} / R_{r}$

$\omega_{r} \quad$ motor angular velocity

The state observer, which estimates the stator current and the rotor flux together, is written as the following equation.

$$
\frac{d}{d t} \hat{x}=\hat{A} \hat{x}+\boldsymbol{B} v_{s}+\boldsymbol{G}\left(\hat{i}_{s}-i_{s}\right)
$$

where ${ }^{\wedge}$ means the estimated values and $\boldsymbol{G}$ is the observer gain matrix which is decided so that (3) can be stable.

\section{B. Adaptive Scheme for Speed Estimation}

When speed sensors cannot be mounted, unknown parameters are included in the state observer equation (3). The adaptive observer shown in Fig. 1 is one solution for estimating the states and unknown parameters together. Therefore, we proposed the addition of an adaptive scheme for estimating the rotor speed $\hat{\omega}_{r}$ in the matrix $\hat{A}$.

In order to derive the adaptive scheme, Lyapunov's theorem is utilized. From (1) and (2), the estimation error of the stator 


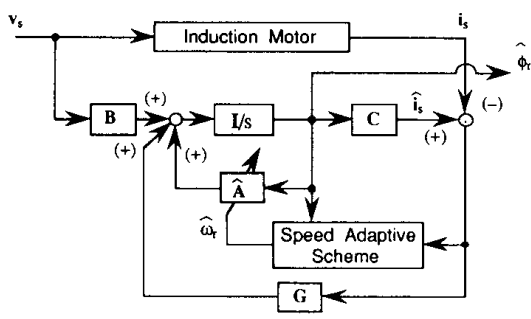

Fig. 1. Block diagram of speed adaptive observer.

current and rotor flux is described by the following equation.

$$
\frac{d}{d t} e=(\boldsymbol{A}+\boldsymbol{G C}) e-\Delta \boldsymbol{A} \hat{x}
$$

where

$$
\begin{aligned}
e & =x-\hat{x} . \\
\Delta \boldsymbol{A} & =\hat{\boldsymbol{A}}-\boldsymbol{A}=\left[\begin{array}{cc}
0 & -\Delta \omega_{r} \boldsymbol{J} / c \\
0 & \Delta \omega_{r} \boldsymbol{J}
\end{array}\right] . \\
c & =\left(\sigma L_{s} L_{r}\right) / M, \Delta \omega_{r}=\hat{\omega}_{r}-\omega_{r} .
\end{aligned}
$$

Now, we define the following Lyapunov function candidate.

$$
V=e^{T} e+\left(\hat{\omega}_{r}-\omega_{r}\right)^{2} / \lambda
$$

where $\lambda$ is a positive constant.

The time derivative of $V$ becomes

$$
\begin{aligned}
\frac{d}{d t} V= & e^{T}\left\{(\boldsymbol{A}+\boldsymbol{G} \boldsymbol{C})^{T}+(\boldsymbol{A}+\boldsymbol{G C})\right\} e \\
& -2 \Delta \omega_{r}\left(e_{i d s} \hat{\phi}_{q r}-e_{i q s} \hat{\phi}_{d r}\right) / c \\
& +2 \Delta \omega_{r} \frac{d}{d t} \hat{\omega}_{r} / \lambda
\end{aligned}
$$

where $e_{i d s}=i_{d s}-\hat{i}_{d s}, e_{i q s}=i_{q s}-\hat{i}_{q s}$.

From (6), we can find the following adaptive scheme for the speed estimation by equalizing the second term to the third term.

$$
\frac{d}{d t} \hat{\omega}_{r}=\lambda\left(e_{i d s} \hat{\phi}_{q r}-e_{i q s} \hat{\phi}_{d r}\right) / c
$$

If we decide the observer gain matrix $\boldsymbol{G}$ so that the first term of (6) can be negative-semidefinite, the proposed speed adaptive flux observer is stable.

The motor speed can change quickly. Therefore, the following proportional and integral adaptive scheme is used practically in order to improve the response of the speed estimation.

$$
\hat{\omega}_{r}=K_{P}\left(e_{i d s} \hat{\phi}_{q r}-e_{i q s} \hat{\phi}_{d r}\right)+K_{I} \int\left(e_{i d s} \hat{\phi}_{q r}-e_{i q s} \hat{\phi}_{d r}\right) d t
$$

where $K_{P}, K_{I}$ is the arbitrary positive gain.

\section{Experimental Results of Speed Estimation}

The characteristics of the proposed speed estimation method is verified by experimentation. The observer gain matrix $\boldsymbol{G}$ is calculated by the following equation so that the observer poles

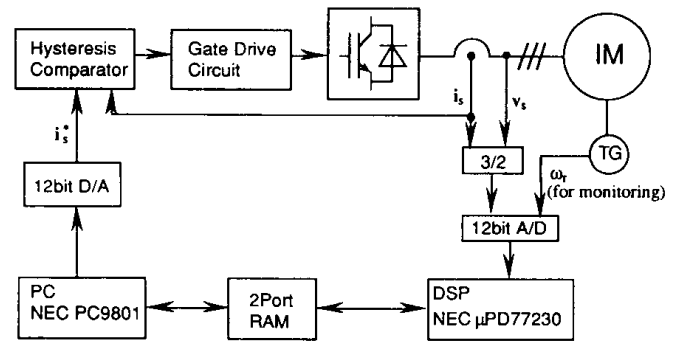

Fig. 2. System configuration.

TABLE I

Ratings of Tested INDUCtion MotoR

\begin{tabular}{ccc}
\hline $3.7 \mathrm{~kW}$ & $200 \mathrm{~V}$ & $15 \mathrm{~A}$ \\
Four poles & $50 \mathrm{~Hz}$ & $1420 \mathrm{r} / \mathrm{min}$ \\
\hline
\end{tabular}

are proportional to those of the induction motor (proportional constant $k>0$ ) [6].

$$
\begin{aligned}
& \boldsymbol{G}=\left[\begin{array}{rrrr}
g_{1} & g_{2} & g_{3} & g_{4} \\
-g_{2} & g_{1} & -g_{4} & g_{3}
\end{array}\right]^{T} \\
& g_{1}=(k-1)\left(a_{r 11}+a_{r 22}\right) \\
& g_{2}=(k-1) a_{i 22} \\
& g_{3}=\left(k^{2}-1\right)\left(c a_{r 11}+a_{r 21}\right)-c(k-1)\left(a_{r 11}+a_{r 22}\right) \\
& g_{4}=-c(k-1) a_{i 22}
\end{aligned}
$$

An induction motor itself is stable, so the adaptive observer is also stable in usual operation.

Fig. 2 shows a system configuration for experimentation. Equations ( 3 ) and (8) are descretized by the Euler method and implemented on a DSP. A sampling period is $150(\mu \mathrm{s})$. The stator voltage and stator current are detected with 12 bit A$\mathrm{D}$ converters through low-pass filters, the cutoff frequency of which is $1(\mathrm{kHz})$. A tachometer generator, TG, is used as a speed sensor for monitoring. Experimental data are acquired by sending them to a PC (NEC9801) from a DSP through 2 port RAM's.

Fig. 3 shows the results of estimating the speed of the induction motor, the ratings of which are shown in Table I. Then the proportional constant $k$ in (10)-(13) is 1.0 , i.e., $\boldsymbol{G}=0$, for simplifying the DSP program. The induction motor rotates at constant speed $(100 \mathrm{r} / \mathrm{min})$ under the no-load condition. An initial value of the estimated speed is zero.

With the large PI gains for the adaptive scheme, $K_{P}$ and $K_{I}$, the convergence for the speed estimation is fast; however, a lot of higher harmonic components are included in the estimated speed. These harmonic components are caused by the PWM. Therefore, the PI gains have to be limited when the stator voltage and current are acquired asynchronously with the PWM pattern. If a direct digital PWM control method [7] is used, that problem and the low pass filters for data acquisition can be removed. 


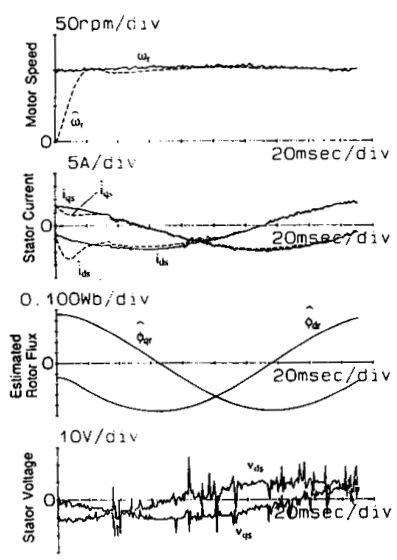

(a)
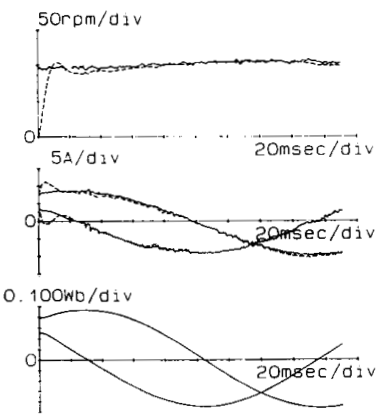

$10 \mathrm{~V} / \mathrm{aiv}$

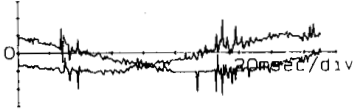

(b)
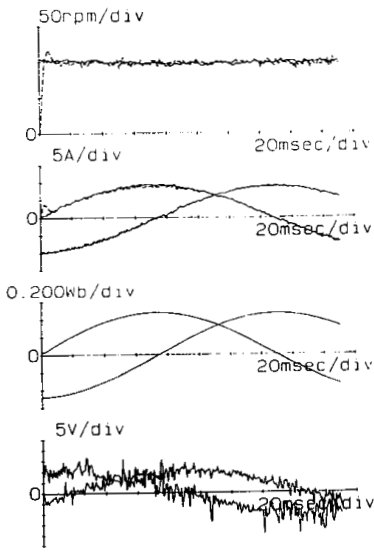

(c)

Fig. 3. Behavior of speed estimation: (a) $K_{P}=0.6, K_{I}=400$; (b) $K_{P}=1.8, K_{I}=1200$; (c) $K_{P}=6.0, K_{I}=4000$.

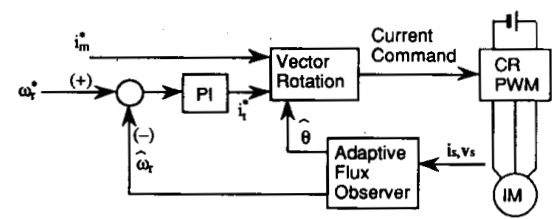

Fig. 4. Block diagram of induction motor control system.

\section{DIRECT FIELD ORIENTED} CONTROL WITHOUT SPEED SENSORS

\section{A. Control System}

The proposed speed adaptive observer is applied to the direct field-oriented control of an induction motor. Fig. 4 is a block diagram of the induction motor control system without speed sensors. In the block of the vector rotation, the stator current command in the stationary reference frame is calculated as follows.

where

$$
\begin{aligned}
& i_{1 d}^{*}=i_{m}^{*} \cos \hat{\theta}-i_{t}^{*} \sin \hat{\theta} \\
& i_{1 q}^{*}=i_{m}^{*} \sin \hat{\theta}+i_{t}^{*} \cos \hat{\theta}
\end{aligned}
$$

$$
\begin{aligned}
& \cos \hat{\theta}=\hat{\phi}_{d r} / \hat{\phi}_{r} . \\
& \sin \hat{\theta}=\hat{\phi}_{q r} / \hat{\phi}_{r} . \\
& \hat{\phi}_{r}=\sqrt{\hat{\phi}_{d r}^{2}+\hat{\phi}_{q r}^{2}} \\
& i_{m}^{*} \text { Field Current Command. } \\
& i_{t}^{*} \quad \text { Torque Current Command. }
\end{aligned}
$$

\section{B. Experimental Results}

For the field oriented control, the following PI gains of the speed adaptive scheme are selected:

$$
K_{P}=1.8, \quad K_{I}=1200 .
$$

Fig. 5 shows experimental results of the forward-reverse operation under the no-load condition. The induction motor
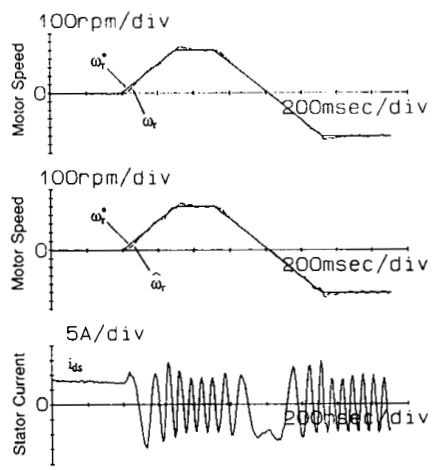

Fig. 5. Experimental results of forward-reverse operation.

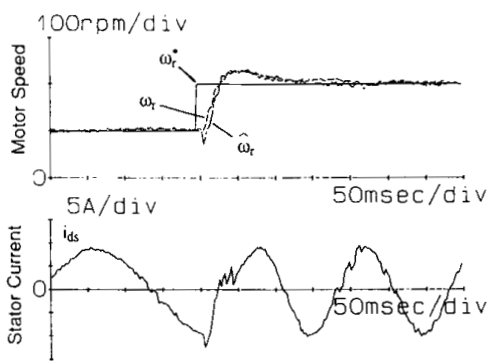

Fig. 6. Step speed response.

operated stably even at zero speed before $t=400(\mathrm{~ms})$. This system can sit still as zero speed for an extended time.

Figs. 6 and 7 show experimental results of a speed step and a load step response, respectively. In the case of Fig. 7, the load torque changes instantaneously from $0(\mathrm{Nm})$ to $17(\mathrm{Nm})$ (0.7 pu).

From these figures, we can find that the proposed speed adaptive flux observer follows the actual speed even in transient states, and the direct field oriented control system works well without speed sensors. 


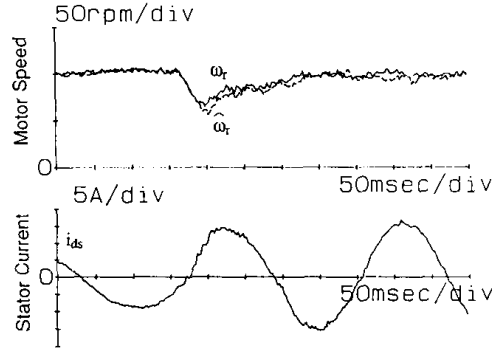

Fig. 7. Step torque response.

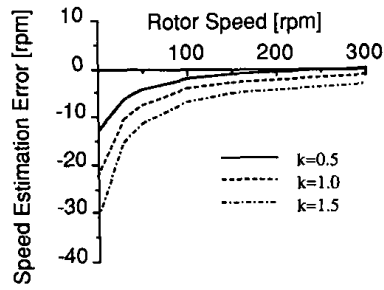

(a)

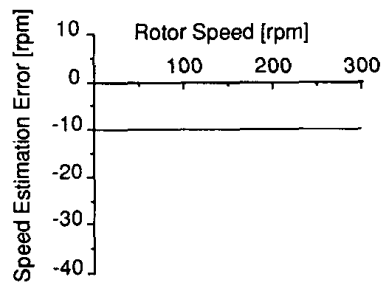

(b)

Fig. 8. Influence of parameter variation on speed estimation: (a) $\hat{R}_{s}=1.2$ $R_{s}$; (b) $\hat{R}_{r}=1.2 R_{r}$

\section{INFLUENCE OF PARAMETER VARIATION ON SPEED ESTIMATION AND ITS COMPENSATION}

\section{A. Influence of Parameter Variation}

The validity of the speed adaptive observer has been verified experimentally. Those results are obtained under the condition that the motor parameters used in the observer are correct. However, it is hard to use the correct parameters, because the stator and rotor resistance vary with the motor temperature. Therefore, we investigate the influence of the parameter variation on the speed estimation and the torque control.

Fig. 8(a) and (b) show speed estimation errors when the nominal values of the stator and rotor resistance are 1.2 times as much as actual ones, respectively. Fig. 9 shows the ratio of the generating torque to the reference when the nominal stator resistance is 1.2 times as much as actual one. These results are obtained by the simulation under the condition that the load torque is $20(\mathrm{Nm})$.

The stator resistance variation has a great influence on the speed estimation and the torque control at a low speed region. On the other hand, the influence of the rotor resistance variation is constant independent of the motor speed. This is because we cannot separate the speed estimation error and the

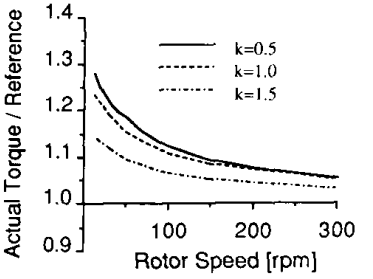

Fig. 9. Influence of stator resistance variation on torque control $\left(\hat{R}_{s}=1.2 R_{s}\right)$.

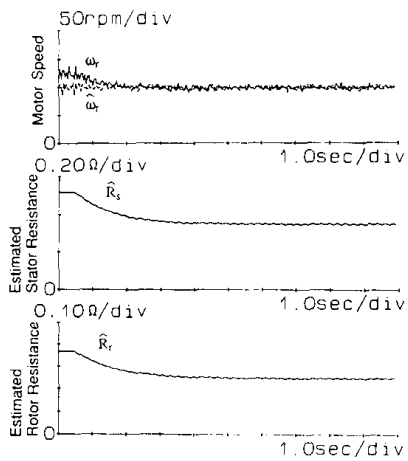

Fig. 10. Behavior of speed and parameter estimation.

rotor resistance error from the stator variables. This is easily understood from the steady state equivalent circuit the rotor resistance of which is $\mathrm{Rr} / \mathrm{s}$ ( $\mathrm{s}$ : slip). For the same reason, the rotor resistance variation does not affect the torque control at all.

\section{B. Compensation for Parameter Variation}

To compensate for these influences, identification of the parameters is necessary. We have proposed the adaptive scheme for the stator and rotor resistance identification in the case that the actual speed can be detected [6]. The proposed rotor resistance adaptive scheme is not applicable to the case without speed sensors. Therefore, we propose the following parameter update law.

$$
\begin{aligned}
\frac{d}{d t} \hat{R}_{s} & =-\lambda_{1}\left(e_{i d s} \hat{i}_{d s}+e_{i q s} \hat{i}_{q s}\right) \\
\hat{R}_{r} & =R_{s m} \hat{R}_{s}
\end{aligned}
$$

where $\lambda_{1}$ is arbitrary positive constant, $R_{s r n}$ is the ratio of the nominal values of the stator and rotor resistance, and parameters are updated only in a powering operation.

The adaptive scheme for the stator resistance (17) is derived by the same way as that for the speed [6]. The rotor resistance is made proportional to the stator resistance which is identified adaptively, because the both resistances change with the operating temperature.

Fig. 10 shows experimental results of the parameter identification. In this experiment, the speed command and the load torque are constant at $100(\mathrm{rpm})$ and $20(\mathrm{Nm})$, respectively. 
The initial values of the stator and rotor resistance are 1.5 times as much as the nominal ones and the positive constant $\lambda_{1}$ is 0.01 . The estimated speed agrees with the actual speed after the estimated parameter conversion. From this experimentation, the validity of the proposed parameter update law is verified.

\section{CONCLUSION}

This paper has presented a new method for estimating a rotor flux and speed of an induction motor based on the adaptive control theory. The proposed method can be applied to a direct field oriented induction motor control without speed sensors. The influence of the parameter variation on the speed estimation can be removed by the proposed parameter adaptive scheme. The validity of the adaptive flux observer has been verified using experimentation.

\section{ACKNOWLEDGMENT}

The authors would like to thank M. Ozaki of Mitsubishi Electric Co. for his assistance.

\section{REFERENCES}

[1] T. Ohtani, N. Takada, and K. Tanaka, "Vector control of induction motor without shaft encoder," in Conf. Rec. 1989 IEEE IAS Annu. Mtg., pp. 500-507.

[2] C. Schauder, "Adaptive speed identification for vector control of induction motor without rotational transducers," in Conf. Rec. 1989 IEEE IAS Annu. Mtg., pp. 493-499.

[3] U. Baader, M. Depenbrock, and G. Gierse, "Direct self control of inverter-fed induction machine," in Conf. Rec. 1989 IEEE IAS Annu. Mtg. pp. 486-492.

[4] X. Xu and D. W. Novotny, "Implementation of direct stator flux orientation control on a versatile DSP based system," in Conf. Rec. 1990 IEEE IAS Annu. Mtg., pp. $404-409$.

[5] Y. Xue, X. Xu, T. G. Habetler, and D. M. Divan, "A low cost stator flux oriented voltage source variable speed drives," in Conf. Rec. 1990 IEEE IAS Annu. Mtg. pp. 410-415.

[6] H. Kubota, K. Matsuse, and T. Nakano, "New adaptive flux observer of induction motor for wide speed range motor drives," in Conf. Rec. IEEE IECON'90 pp. 921-926.

[7] L. B. Brahim and A. Kawamura, "Digital current regulation of field oriented controlled induction motor based on predictive flux observer," in Conf. Rec. 1989 IEEE IAS Annu. Mtg., pp. 486-492.

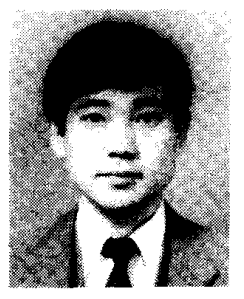

Hisao Kubota (M'87) was born in Kawasaki, Japan, on January 4, 1960. He received the B.E., M.E., and $\mathrm{Ph} . \mathrm{D}$. degrees in electrical engineering from Meiji University, Japan, in 1982, 1984, and 1989, respectively.

Since 1984, he has been a Research Assistant at Meiji University in the Department of Electrical Engineering. His research interests are in ac drives, motion control, and power electronics.

Dr. Kubota is a member of the Institute of Electrical Engineers of Japan and the Society of Instrument and Control Engineers, Japan. He is also a member of the IEEE Industry Applications, Industrial Electronics, and Power Electronics Societies.

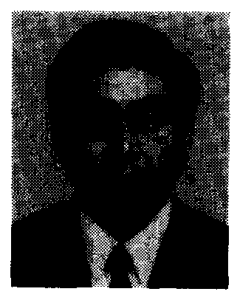

Kouki Matsuse (SM'88) was born in Tsingtao, China, on August 6, 1943. He received the B.E., M.E., and Ph.D. degrees in electrical engineering from Meiji University, Tokyo, Japan, in 1966, 1968, and 1971 , respectively.

In 1971, he joined the faculty at Meiji University as a Lecturer of Electrical Engineering. From 1974 to 1979, he was an Associate Professor at Meiji University. Since 1979, he has been a Professor in the Department of Electrical Engineering at Meiji University. In 1980 he was a Visiting Professor of Electrical Engineering at Iowa State University for five months. He has published over 80 technical articles in the field of power electronics and ac machines, and he holds three U.S. patents. His research interests are in power electronics, automatic control, adjustable-speed drives, electrical linear actuators, and ac machines.

Dr. Matsuse received the Outstanding Paper Award in 1992 from the Institute of Electrical Engineers of Japan. He is a member of the Institute of Electrical Engineers of Japan and the Society of Instrument and Control Engineers of Japan.

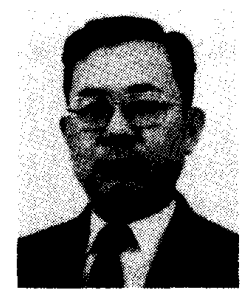

Takayoshi Nakano was born in Tokyo, Japan, on September 28, 1936. He received the B.S. degree in electrical engineering from Waseda University, Tokyo, Japan, in 1960.

In 1960, he joined Fuji Electric Co., Ltd., where he has been engaged in the research and development of power electronics and variable speed drive systems for general industries. Presently he is an Executive Managing Director with Fuji Electric Corporate Research and Development Ltd., Tokyo. Electrical Engineers of Japan. 